\title{
Water restriction and physiological traits in soybean genotypes contrasting for nitrogen fixation drought tolerance
}

\author{
Paula Cerezini ${ }^{1}$, Dáfila dos Santos Lima Fagotti ${ }^{2}$, Antonio Eduardo Pípolo ${ }^{3}$, Mariangela Hungria ${ }^{3}$, Marco Antonio Nogueira ${ }^{3 *}$
}

\author{
${ }^{1}$ State University of Londrina - Dept. of Microbiology, Rod. \\ Celso Garcia Cid, Pr 445, km 380 - 86057-970 - Londrina, \\ PR - Brazil. \\ ${ }^{2}$ State University of Londrina - Dept. of Agronomy. \\ ${ }^{3}$ Embrapa Soybean, Rod. Carlos João Strass, s/n, C.P. 231 \\ - 86001-970 - Londrina, PR - Brazil. \\ *Corresponding author <marco.nogueira@embrapa.br>
}

Edited by: Fernando Dini Andreote

Received December 10, 2015

Accepted June 02, 2016
ABSTRACT: Biological nitrogen fixation (BNF) is essential to the economic viability of the soybean [Glycine max (L.) Merrill] crop in Brazil, but drought may impair the BNF processes. We evaluated physiological traits of nitrogen fixation drought-tolerant (NFDT) (R01-581F, R01-416F and R02-1325) and drought-susceptible (CD 215 and BRS 317) genotypes of soybean subjected to drought or regular water supply between 45 and 55 days after emergence, in an experiment under greenhouse conditions in pots containing non-sterile soil. R01-581F had more stable photosynthetic and transpiration rates, and higher intercellular $\mathrm{CO}_{2}$ levels under drought. Drought reduced the chlorophyll concentration in all genotypes, but with less intensity in R01-581F and R02-1325. The NFDT genotypes generally showed higher concentrations of $\mathrm{N}, \mathrm{K}$ and $\mathrm{Mn}$ in shoots, irrespective of the water condition. Exposure to drought increased total soluble sugars in nodules in all genotypes, as well as the concentrations of ureides in leaves and nodules, whereas ureides in petioles increased only in the susceptible genotypes. Drought negatively affected photosynthetic and BNF attributes; however, R01-581F showed the best performance, with potential for use in breeding programs aiming at drought-tolerant varieties.

Keywords: Glycine max, abiotic stress, nodulation, total soluble sugars, ureides

\section{Introduction}

The capacity to form symbiosis with nitrogenfixing Bradyrhizobium makes the soybean [Glycine max (L.) Merrill] crop independent of N-fertilizers, especially in Brazil. However, drought compromises plant performance in general and the biological nitrogen fixation $(\mathrm{BNF})$ process, and negatively affects the plant $\mathrm{N}$ supply (Sinclair et al., 2007; Sinclair and Vadez, 2012). Climate changes are expected to reduce rainfall in subtropical areas by $20 \%$ (IPCC, 2007), increase the frequency of drought and cause losses to soybean crop yields. Studies have indicated that the combination of three mechanisms may impair the BNF under drought: (1) limitation of oxygen supply to nodules (King and Purcell, 2001); (2) shortage of carbon supply to bacteroids due to reductions in the activity of sucrose synthase (SS) (Arrese-Igor et al., 2011); and (3) regulation of $\mathrm{N}$ metabolism by feedback of $\mathrm{N}$ compounds, mainly ureides (Purcell et al., 2000; Collier and Tegeder, 2012).

BNF performance under drought affects different soybean genotypes differently (King and Purcell, 2006; Sinclair et al., 2007). 'Jackson' (PI 548657), characterized as nitrogen fixation drought tolerant (NFDT), has been crossed with KS4895 (PI 595081), which has higher yield potential resulting in the breed lines R01581F (PI 647961) and R01-416F (PI 647960). These lines have shown higher $\mathrm{N}$ accumulation in shoots and higher BNF rates under drought, in addition to higher potential for grain yields under non-irrigated conditions in relation to the parental KS4895 (Chen et al., 2007). In studies searching for elite lines with high grain yield potential, the genotype R02-1325 showed improved drought-related physiological traits, including NFDT (Devi et al., 2014). However, the NFDT phenotype needs confirmation based on physiological studies to understand the mechanisms involved.

The aim of this study was to investigate possible mechanisms involved in the inhibition/tolerance of BNF and performance of soybean genotypes with different levels of drought tolerance under regular and restricted water supply.

\section{Materials and Methods}

\section{Experimental setup}

The experiment was conducted under greenhouse conditions in Londrina, Paraná, Brazil $\left(23^{\circ} 11^{\prime} 28.77^{\prime \prime} \mathrm{S}\right.$, $\left.51^{\circ} 11^{\prime} 1.42^{\prime \prime} \mathrm{W}\right)$. The design was entirely randomized, in a $5 \times 2$ factorial arrangement, with seven replications. The NFDT soybean genotypes R01-581F, R01-416F and R02-1325 (Chen et al., 2007), and the drought-susceptible genotypes, CD 215 and BRS 317 (Cerezini et al., 2014), were subjected to two levels of water condition, wet and dry, between 45 and 55 days after emergence (DAE).

A topsoil sample $(0-20 \mathrm{~cm})$ from an agricultural site cropped with soybean, classified as Typic Acrudox (USDA, Soil Taxonomy), was used as substrate. Soil chemical analysis revealed: $\mathrm{pH}\left(\mathrm{CaCl}_{2}\right)=4.7$; organic matter $=33 \mathrm{~g} \mathrm{~kg}^{-1} ; \mathrm{P}$ (Mehlich I) $=2.14 \mathrm{mg} \mathrm{dm}^{-3} ; \mathrm{K}$ $=0.31 \mathrm{cmol}_{\mathrm{c}} \mathrm{dm}^{-3}, \mathrm{Ca}=4.02 \mathrm{cmol}_{\mathrm{c}} \mathrm{dm}^{-3}, \mathrm{Mg}=0.64$ $\mathrm{cmol}_{\mathrm{c}} \mathrm{dm}^{-3}, \mathrm{H}+\mathrm{Al}=5.6 \mathrm{cmol}_{\mathrm{c}} \mathrm{dm}^{-3}$, cation exchange capacity $(\mathrm{CEC})=10.5 \mathrm{cmol}_{\mathrm{c}} \mathrm{dm}^{-3}$, sum of bases $(\mathrm{SB})$ $=4.97 \mathrm{cmol}_{\mathrm{c}} \mathrm{dm}^{-3}, \mathrm{~V}=47 \%, \mathrm{Al}=0 \mathrm{cmol}_{\mathrm{c}} \mathrm{dm}^{-3}$; particle size fraction: sand $=732 \mathrm{~g} \mathrm{~kg}^{-1}$, silt $=30 \mathrm{~g} \mathrm{~kg}^{-1}$, clay $=238 \mathrm{~g} \mathrm{~kg}^{-1}$. Based on chemical analysis, the soil 
received dolomitic limestone to raise $\mathrm{pH}\left(\mathrm{CaCl}_{2}\right)$ to 6.5 . Aliquots of the substrate were placed into plastic pots of $8 \mathrm{~kg}$, watered, and incubated for 30 days to complete the neutralization reaction. Before sowing, each pot received $106 \mathrm{mg}$ of $\mathrm{P}, 630 \mathrm{mg}$ of $\mathrm{K}$ (both as $\mathrm{K}_{2} \mathrm{HPO}_{4}$ ), 460 $\mathrm{mg}$ of $\mathrm{Mg}, 620 \mathrm{mg}$ of $\mathrm{S}$ (both as $\mathrm{MgSO}_{4} .7 \mathrm{H}_{2} \mathrm{O}$ ) and $50 \mathrm{~mL}$ of micronutrient solution containing $1.14 \mathrm{mg}$ of $\mathrm{CoSO}_{4}$ $4.34 \mathrm{mg}$ of $\mathrm{Na}_{2} \mathrm{MO}_{4}$ and $400 \mathrm{mg}$ of $\mathrm{H}_{3} \mathrm{BO}_{3}$ per liter of water. Seeds were inoculated with a mixture of Bradyrhizobium japonicum (strain SEMIA 5079) and B. diazoefficiens (strain SEMIA 5080), as recommended in commercial inoculants in Brazil, just before sowing, using a broth containing $1 \times 10^{9}$ viable cells $\mathrm{mL}^{-1}$. Each pot received eight seeds that were thinned to three seedlings per pot one week later.

The soil water-holding capacity was determined in a tension table and Richards' extractor device (Richards and Fireman, 1943), which allowed for the construction of a water-retention curve and determination of soil water potential $\left(\psi_{\mathrm{w}}\right)$. During the first $45 \mathrm{DAE}$, plants received water daily to maintain the $\psi_{\mathrm{w}}$ at $-13 \mathrm{kPa} / 300$ $\mathrm{mL}$ of water per $\mathrm{L}$ of soil), which represents a fraction of available water (FAW) of 0.9. After $45 \mathrm{DAE}$, during the flowering stage, seven pots of each genotype were subjected to drought for 10 days at $\psi_{\mathrm{w}}=-200 \mathrm{kPa}(90$ $\mathrm{mL}$ of water per $\mathrm{L}$ of soil), with an FAW of 0.27 . The remaining seven control pots continued to receive regular water supply. Soil moisture was monitored daily by weighing the pots on an electronic scale, with correction of moisture accordingly in the morning period (between 8-10 h a.m.). The mass of plants under wet conditions at 45 DAE was taken into account to correct the effect of plant weight on water reposition within the period under drought. The average temperature ranged from 21.9 to $37.2^{\circ} \mathrm{C}$, and the average relative humidity from 38 to $83 \%$.

\section{Measurements}

During the 10 days of drought simulation, SPAD (Soil Plant Analysis Development, Konica Minolta Sensing Inc., Osaka, Japan) units were measured between 8-10 h a.m. in the third recently expanded trifoliolates with a portable meter, model SPAD-502. Since the SPAD index expresses the intensity of leaf green and correlates with the content of leaf chlorophyll, results were converted into leaf-chlorophyll content $\left(\mu \mathrm{g} \mathrm{cm}^{-2}\right)$ (Kaschuk et al., 2010).

On the tenth ${ }^{\text {th }}$ day under drought, physiological parameters were measured in plants in both water conditions using a portable gas-exchange meter. Measurements included stomatal conductance, net photosynthetic rate, transpiration rate and intercellular $\mathrm{CO}_{2}$ concentration. Gas exchanges were measured in the central trifolium of the last fully expanded trifoliate, in one plant per pot, in the morning (9-11 $\mathrm{h}$ a.m.).

By the end of the $10^{\text {th }}$ day under drought simulation, $55 \mathrm{DAE}$, all plants were harvested. Roots were collected and 30 fresh nodules per pot were weighed, immediately frozen in liquid $\mathrm{N}_{2}$ and stored at $-80{ }^{\circ} \mathrm{C}$ for further analyses. The remaining nodules were collected, weighed and counted; the dry weight of frozen nodules was estimated based on the dry/fresh weight ratio of the remaining nodules. Shoots and roots were dried at $60{ }^{\circ} \mathrm{C}$ for $48 \mathrm{~h}$ for determination of dry weight.

Nitrogen (N) was determined in sulfuric extracts by colorimetry (Searle, 1984); potassium (K) was determined in nitric-perchloric extracts by atomic absorption spectrophotometry; manganese ( $\mathrm{Mn}$ ) by optical emission spectrometry with inductively coupled plasma.

Total soluble sugars (TSS) in shoots were extracted according to Carvalho et al. (1998) with modifications. Samples of dry tissue (200 $\mathrm{mg}$ ) were extracted three times with $10 \mathrm{~mL}$ of $80 \%$ ethanol at $80{ }^{\circ} \mathrm{C}$ for $15 \mathrm{~min}$ and centrifugation at $925 \mathrm{~g}$ for $15 \mathrm{~min}$, and determined in the supernatant by the anthrone method (Yemm and Willis, 1954) using glucose at $60 \mathrm{mg} \mathrm{mL}^{-1}$ as standard. TSS in nodules were extracted and determined as before, but using glucose at $1 \mathrm{mg} \mathrm{mL}^{-1}$ as standard.

Dry leaves, petioles and nodules were grinded separately and extracts used for determination of ureides (Vogels and van der Drift, 1970).

\section{Statistical analysis}

The dataset was submitted to a two-way ANOVA $(p \leq 0.05)$, considering an entirely randomized design, in a $5 \times 2$ factorial arrangement. The effects of factors or their interactions were compared by Tukey's test $(p \leq 0.05)$.

\section{Results}

Drought reduced the shoot dry mass by $26 \%$ (Figure $1 \mathrm{~A})$, whereas root dry mass increased (Figure 1B) the average of the genotypes by $12 \%$. R01-416F produced more nodule mass under drought than R01-581F and CD 215 (Figure 1C); moreover, drought did not affect the nodule mass in R01-416F, but reduced it in the other genotypes. A higher number of nodules occurred in R02-1325, irrespective of the water condition (Figure 1D), differing only from CD 215. Drought reduced the number of nodules by $21 \%$ using a calculated average of the genotypes.

In general, the NFDT genotypes showed higher accumulation of $\mathrm{N}, \mathrm{K}$ and $\mathrm{Mn}$ (mg per pot) in leaves, regardless of the water condition (Table 1). Higher $\mathrm{N}$ accumulation occurred in R01-581F and R01-416F compared with the other genotypes, under both water conditions. $\mathrm{K}$ content varied amongst the genotypes, with higher values in R01-416F under drought and CD 215 under wet conditions. Although all genotypes had shown a reduction of $\mathrm{K}$ accumulated in the shoot when exposed to drought, R01-581F and R01$416 \mathrm{~F}$ showed less reduction compared with the remaining genotypes. Mn content was higher in NFDT genotypes under wet conditions, whereas R01-581F stood out under drought with the highest accumu- 

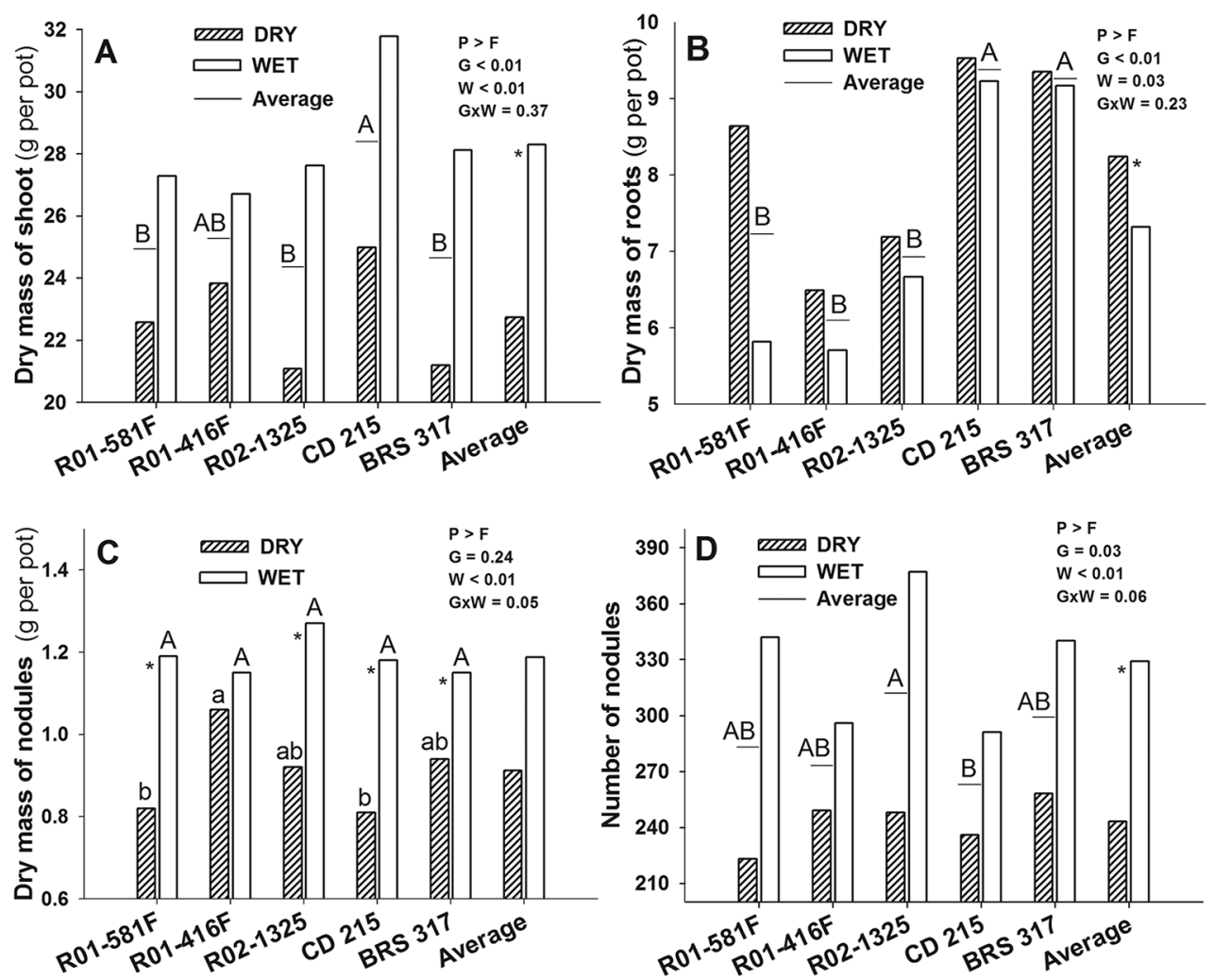

Figure 1 - Shoot (A) and root dry weight (B), nodule dry weight (C), and number of nodules (D) in soybean genotypes that show (R01-581F, R01-416F, and R02-1325) or not (CD 215, and BRS 317) $\mathrm{N}_{2}$ fixation drought tolerance, kept under wet or dry conditions between 45 and 55 days after emergence. Means followed by the same letters do not differ from one another (Tukey, $p \leq 0.05$ ); capital letters on top of columns compare genotypes under wet conditions; small letters on top of columns compare genotypes under dry conditions; capital letters underlined compare genotypes independent of water condition (non-significant interaction); * significant effect between water condition on each genotype ( $n=7$ for $C$ ) or on the average of genotypes ( $n=35$ for $A, B$ and D). $G=$ Genotypes; $W=$ Water condition; $G \times W=$ interaction between genotypes and water condition.

Table 1 - Total N, K and Mn accumulation in shoot of soybean genotypes that show (R01-581F, R01-416F, R02-1325) or not (CD 215 and BRS 317) $\mathrm{N}_{2}$ fixation drought tolerance, kept under wet or dry conditions between 45 and 55 days after emergence.

\begin{tabular}{|c|c|c|c|c|c|c|}
\hline \multirow{2}{*}{ Water condition } & \multicolumn{6}{|c|}{ Genotypes } \\
\hline & R01-581F & R01-416F & $\mathrm{R} 02-1325$ & CD 215 & BRS 317 & Average \\
\hline & & & (mg per po & & & \\
\hline DRY & $706 \mathrm{Ab}$ & $653 \mathrm{Ab}$ & $572 \mathrm{Bb}$ & $479 \mathrm{Cb}$ & $459 \mathrm{Cb}$ & 574 \\
\hline WET & $921 \mathrm{Aa}$ & $886 \mathrm{Aa}$ & $800 \mathrm{Ba}$ & $722 \mathrm{Ca}$ & $559 \mathrm{Da}$ & 778 \\
\hline Average & 814 & 770 & 686 & 601 & 509 & \\
\hline \multicolumn{7}{|c|}{ ANOVA: genotype $(G)<0.01$, water condition $(\mathrm{W})<0.01, \mathrm{G} \times \mathrm{W}=0.031$} \\
\hline & & 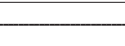 & (mg per pot & ( & (2) & \\
\hline DRY & $402 \mathrm{ABb}$ & $439 \mathrm{Ab}$ & $389 \mathrm{Bb}$ & $395 \mathrm{ABb}$ & $309 \mathrm{Cb}$ & 387 \\
\hline WET & $497 \mathrm{ABCa}$ & $480 \mathrm{BCa}$ & $523 \mathrm{ABa}$ & $538 \mathrm{Aa}$ & $463 \mathrm{Ca}$ & 500 \\
\hline Average & 449 & 460 & 456 & 467 & 386 & \\
\hline \multicolumn{7}{|c|}{ ANOVA: genotype $(G)<0.01$, water condition $(W)=0.017, G \times W=0.048$} \\
\hline & & & (mg per po & & 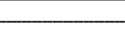 & \\
\hline DRY & $153 \mathrm{Ab}$ & $109 \mathrm{Bb}$ & $93 \mathrm{Bb}$ & $98 \mathrm{Ba}$ & $83 \mathrm{Bb}$ & 107 \\
\hline WET & $254 \mathrm{Aa}$ & $147 \mathrm{Ca}$ & $212 \mathrm{Ba}$ & $107 \mathrm{Da}$ & $119 \mathrm{CDa}$ & 168 \\
\hline Average & 204 & 128 & 153 & 103 & 102 & \\
\hline
\end{tabular}

ANOVA: genotype $(\mathrm{G})<0.01$, water condition $(\mathrm{W})<0.01, \mathrm{G} \times \mathrm{W}<0.01$.

Means followed by the same letter do not differ from one another (Tukey, $p<0.05$ ). Capital letters compare the different genotypes within lines, small letters compare the water conditions within columns. 
lation. On average, the NFDT genotypes showed 23 $\%$ more $\mathrm{Mn}$ accumulation under drought, and $45 \%$ more under regular water supply, compared to the susceptible genotypes.

Water conditions interacted with genotypes for net photosynthetic and transpiration rates, and intercellular $\mathrm{CO}_{2}$ concentration. R01-581F maintained the net photosynthetic rate (Figure 2A), had a higher transpira- tion rate (Figure $2 \mathrm{~B}$ ) and intercellular $\mathrm{CO}_{2}$ concentration (Figure 2C) under drought, whereas the other genotypes had a reduction in these variables. The NFDT genotypes reduced the intercellular $\mathrm{CO}_{2}$ by $20 \%$ under drought, whereas the susceptible genotypes reduced by $35 \%$ as compared to under wet conditions. Drought reduced stomatal conductance by $70 \%$ (Figure 2D), irrespective of the genotype.
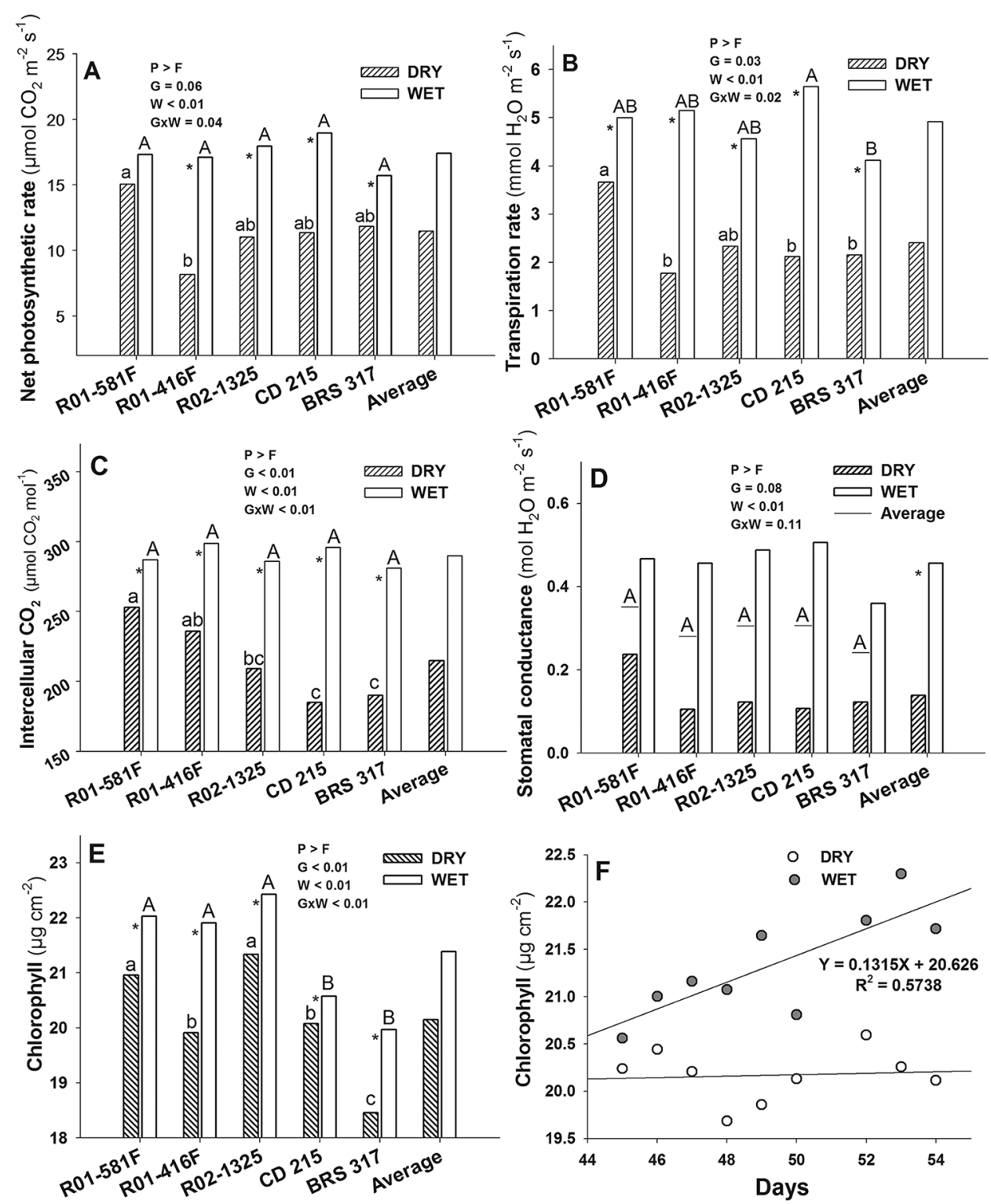

Figure 2 - Net photosynthetic (A) and transpiration (B) rates, intercellular $\mathrm{CO}_{2}$ concentration (C), stomatal conductance (D) and chlorophyll concentrations ( $E$ ) (measured at $54^{\text {th }}$ day), and chlorophyll concentration during the stress period (F) in soybean genotypes that show $\mathrm{N}_{2}$ fixation drought tolerance (R01-581F, R01-416F, and R02-1325) or susceptible (CD 215, and BRS 317), kept under wet or dry conditions between 45 and 55 days after emergence. Means followed by the same letters do not differ from one another (Tukey, $p \leq 0.05$ ); capital letters on top of columns compare genotypes under wet conditions; small letters on columns compare genotypes under dry conditions; capital letters underlined compare genotypes based on the average water condition (non-significant interaction); * significant effect between water condition on each genotype ( $n=7$ for $A, B, C$ and $E$ ) or on the average of genotypes ( $n=35$ for $D$ ). $G=$ Genotypes; $W=W a t e r$ condition; $G \times W=$ interaction between genotypes and water condition. 
There was interaction between genotypes and water condition for chlorophyll concentration (Figure $2 \mathrm{E})$ and variation of chlorophyll concentrations during the period under drought (Figure 2F). Drought reduced the chlorophyll concentrations in all genotypes; BRS 317 showed the lowest, whereas R01-581F and R0-1325 showed the highest concentrations (Figure 2E). During the 10 days of exposure to drought, average chlorophyll concentration in plants under drought remained constant, but increased by $7 \%$ in plants with regular water supply (Figure 2F).

The TSS concentrations in the shoots varied with the genotype and water condition. Drought increased TSS in the R01-416F shoots by $42 \%$, whereas R01-581F and R02-1325 were not affected; CD 215 and BRS 317 showed a TSS reduction of $30 \%$ under drought (Figure $3 \mathrm{~A})$. The TSS concentration in fresh nodules showed only isolated effects of the factors (Figure 3B). Overall, there was an increase of $59 \%$ under drought; R01-581F, R02-1325, and CD 215 had the highest concentrations of TSS in fresh nodules, whereas R01-416F showed the lowest concentration, independent of the water condition.

The concentrations of ureides in petioles increased under drought only in the susceptible genotypes; under wet conditions, the NFDT genotypes showed higher concentrations (Figure 4A). Ureides increased in nodules of all genotypes exposed to drought, but the NFDT genotypes had, in general, higher concentrations as compared with the susceptible ones, especially under dry conditions (Figure 4B). Ureides in leaves showed only isolated effects of genotypes and water condition (Figure 4C), with a general increase of $33 \%$ under drought. The highest concentration was observed in BRS 317, which differed only from CD 215 (Figure 4C).

\section{Discussion}

Drought affects nutritional and physiological processes in plants, and jeopardizes the effectiveness of BNF, especially in soybean (Sinclair et al., 2007). However, there are genotypic variations among soybean cultivars in terms of ability to keep BNF under drought stress (Chen et al., 2007; Sinclair et al., 2007; Cerezini et al., 2014). The genotypes R01-581F and R01-416F were selected for having NFDT phenotype, although the mechanisms related to drought tolerance or sensitivity remain unclear. In our study, drought stress changed physiological attributes like net photosynthetic and transpiration rates, concentrations of nutrients in shoots, and metabolism of $\mathrm{N}$ and $\mathrm{C}$ in the majority of genotypes, with different responses even between genotypes considered NFDT.

Drought rapidly decreased the number and nodule mass between 45 and 55 DAE. Despite a reduction in the number of nodules, R01-416F showed no loss in nodule dry weight under drought. King and Purcell (2001) attributed the higher drought tolerance of 'Jackson' over KS4895 to a higher mass of nodules, as observed for the breeding line R01-416F in our study.

Decrease in shoot dry weight was a clear response to drought, a condition under which plants decreased stomatal conductance, resulting in lower rates of gas exchanges, with overall decreases in $\mathrm{C}$ fixation. Reduction of shoot mass is a strategy to control the loss of water under drought (Ohashi et al., 2006). In addition, plants may also avoid dehydration by changing the allocation pattern of $\mathrm{C}$ between shoots and roots to allow for exploitation of deeper soil layers with longer root systems (Lopes et al., 2011). However, shoot and root dry weights are not considered as good traits for evaluating drought tolerance (Thu et al., 2014).
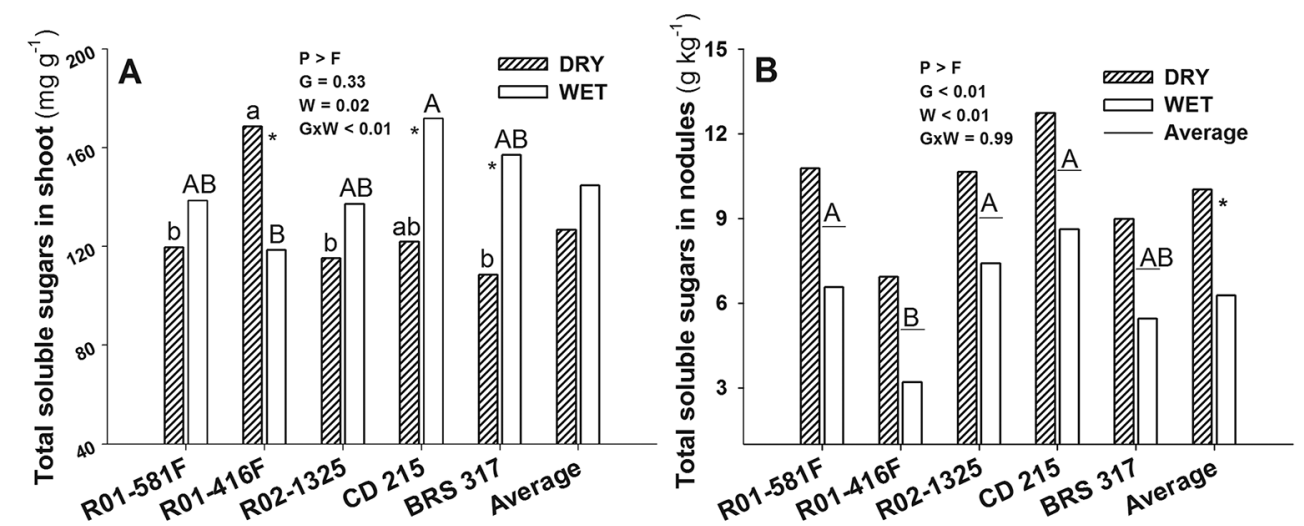

Figure 3 -Total soluble sugar in shoot (A) and fresh nodules (B) in soybean genotypes that show (R01-581F, R01-416F, and R02-1325) or not (CD 215 , and BRS 317) $N_{2}$ fixation drought tolerance, kept under wet or dry conditions between 45 and 55 days after emergence. Means followed by the same letters do not differ from one another (Tukey, $p \leq 0.05$ ); capital letters in columns compare genotypes under wet conditions; small letters on columns compare genotypes under dry conditions; capital letters underlined compare genotypes based on an average water condition (non-significant interaction); * significant effect between water condition on each genotype ( $n=7$ for $A$ ) or on the average of genotypes ( $n=35$ for $B$ ). $G=$ Genotypes; $W=$ Water condition; $G \times W=$ interaction between genotypes and water condition. 

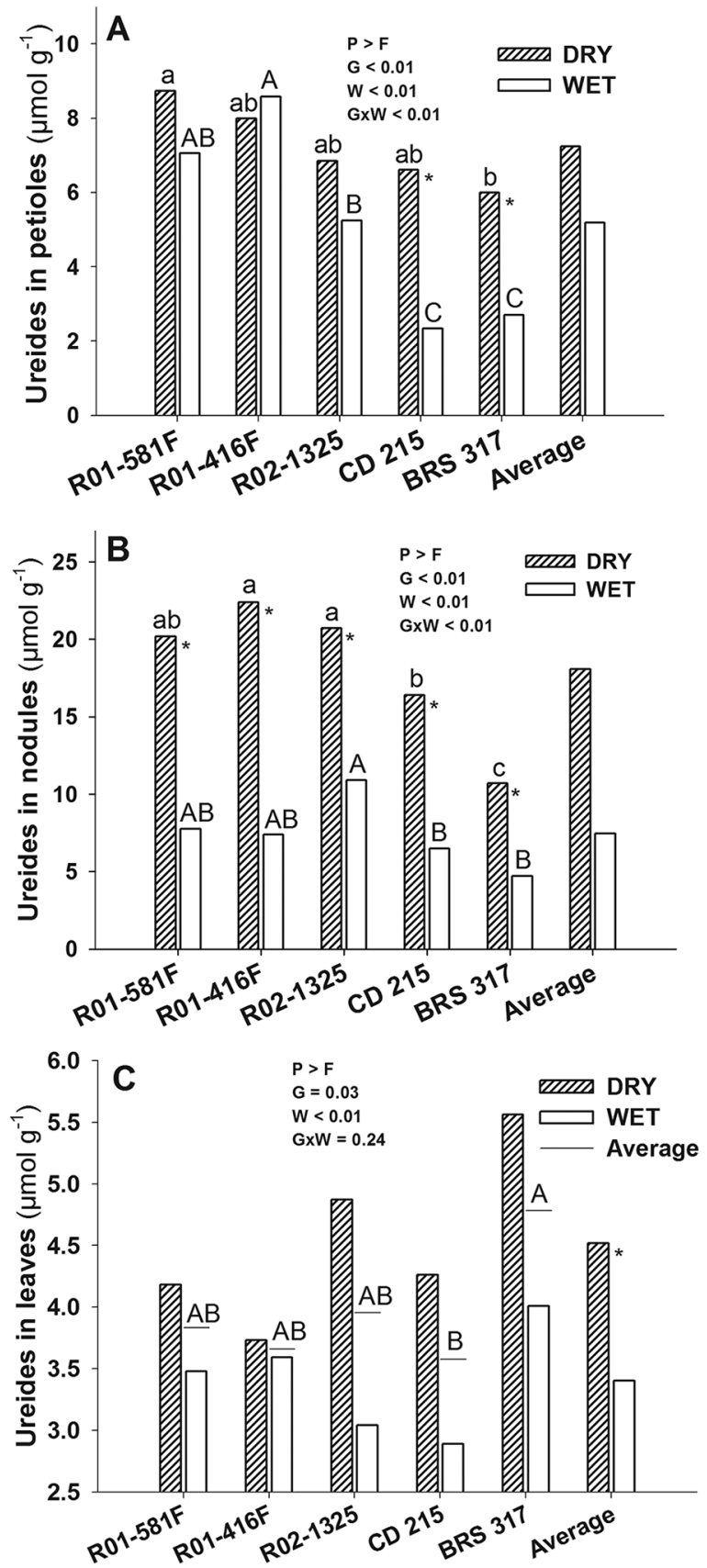

Figure 4 - Ureides in petioles (A), nodules (B), and leaves (C) in soybean genotypes which show (R01-581F, R01-416F, and R021325) or not (CD 215, and BRS 317) $\mathrm{N}_{2}$ fixation drought tolerance, kept under wet or dry conditions between 45 and 55 days after emergence. Means followed by the same letters do not differ from one another (Tukey, $p \leq 0.05$ ); capital letters on columns compare genotypes under wet condition; small letters on columns compare genotypes under dry condition; capital letters underlined compare genotypes based on the average water condition (non-significant interaction); * significant effect between water condition on each genotype ( $n=7$ for $A$ and $B$ ) or on the average of genotypes ( $n=35$ for $\mathrm{C}$ ). $\mathrm{G}=$ Genotypes; $\mathrm{W}=$ Water condition; $\mathrm{G} \times \mathrm{W}=$ interaction between genotypes and water condition.
R01-581F stood out as regards keeping gas exchanges under drought. Despite decreases in dry nodule weight, stomatal conductance and transpiration rate, the net photosynthetic rate did not differ from plants under water sufficiency. This may be associated with the elevation of photorespiration to preserve the photosynthetic apparatus, acting on dissipation of energy (Guan and $\mathrm{Gu}$, 2009). Moreover, the genotypes R01-581F and R02-1325 showed higher concentration of chlorophyll under drought, whereas the other genotypes had a reduction, negatively affecting the photosynthetic performance (Baker and Rosenqvit, 2004). Thus, the maintenance of higher net photosynthetic rates, higher chlorophyll and $\mathrm{N}$ accumulation in shoots suggests that R01-581F has the potential to attenuate yield losses under drought, although trials under field conditions are necessary to confirm this hypothesis. Genotypic variations of soybean under drought have been found for photosynthetic capacity (Fenta et al., 2012), and for plant capacity to keep greater leaf area to resume the photosynthetic process after rainfall or irrigation (James et al., 2008).

The BNF process stimulates the photosynthetic rate and chlorophyll concentrations, and prevents accumulation of carbohydrates in leaves, thereby delaying leaf senescence (Kaschuk et al., 2010). However, these processes are impaired under drought, with increases in TSS and acceleration of leaf senescence. Accumulations of certain osmoregulators and osmoprotectors, such as sugars, organic acids, amino acids and inorganic ions like $\mathrm{K}^{+}$, represent a mechanism of adaptation to drought (Bray, 1997). Thus, the R01-416F tolerance to drought seems related to the maintenance of cell turgidity via osmotic adjustment (James et al., 2008), with accumulation of solutes and consequent decrease of water potential inside the cells. However, accumulation of TSS in shoots, especially in source leaves, may lead to inhibition of photosynthesis (McCormick et al., 2008), which is in agreement with a more intense reduction of the photosynthetic rate and higher accumulation of TSS in the shoots of R01-416F under drought. On the other hand, since the TSS did not change in the shoots of R01-581F and R02-1325 under drought, they seem able to keep the performance in $\mathrm{C}$ assimilation.

Nitrogen commonly limits crop yields under drought (Sinclair and Vadez, 2012) and, therefore, higher N levels in genotypes with NFDT corroborate the findings of Chen et al. (2007), who reported the higher yield potential of R01-581F and R01-416F under drought because of a more effective BNF. Sinclair et al. (2007) observed that more N accumulation in R01-581F and R01-416F might support, within certain limits, the maintenance of grain yield under drought compared with sensitive checks. Studies demonstrated a negative correlation between shoot $\mathrm{N}$ under wet conditions and drought tolerance in soybean genotypes (King and Purcell, 2006; King et al., 2014). This trend was not observed in this study because the NFDT genotypes had higher $\mathrm{N}$ accumulation under wet conditions and a generally better performance under drought, corroborating the findings of Cerezini et al. (2014). 
Higher accumulation of $\mathrm{Mn}$ in the NFDT genotype R01-581F suggests a further attribute inherited from 'Jackson'. Manganese-dependent metabolism of ureides suggests that higher levels of $\mathrm{Mn}$ in leaves may help soybean to cope with accumulation of ureides in shoots under drought (Purcell et al., 2000). Although Vadez and Sinclair (2002) observed the same trend, there is evidence that the enzymatic degradation of ureides in 'Jackson' may not require $\mathrm{Mn}$ as a cofactor. The relative increase of ureides in petioles of the susceptible genotypes in our study was more pronounced than in the NFDT genotypes, although only R01-581F had also presented higher accumulation of $\mathrm{Mn}$ in the shoots under drought.

Streeter (2003) observed a $100 \%$ increase of ureides in soybean shoots exposed to drought for one week. In contrast, the cultivars 'Jackson' and 'Biloxi' did not show changes in concentration of ureides in shoots 6 days after applying a moisture delimited to $25 \%$ of field capacity (Ladrera et al., 2007). Accumulated ureides are toxic for rhizobia and the enzymatic apparatus related to BNF (Vadez et al., 2000); accordingly, accumulation of ureides in nodules because of a delay in transportation to shoots induced by drought is likely to damage BNF (Collier and Tegeder, 2012; Sinclair and Vadez, 2012). In this study, increases of ureides in petioles were more evident in the susceptible genotypes, suggesting that the $\mathrm{N}$-metabolism was more affected than in the NFDT genotypes. Even under adequate water supply, the NFDT genotypes had more ureides in petioles than did the susceptible genotypes, suggesting more effective BNF.

Despite the impairment of BNF under drought being attributed to accumulation of ureides in nodules, it was not possible to identify whether the accumulation resulted from newly synthesized ureides, a failure in its exportation, or an overflow from shoots via phloem (Vadez et al., 2000). Collier and Tegeder (2012) suggested that accumulation of ureides in nodules occurred due to a reduction in the exportation rate. Our results suggest that both mechanisms might be occurring, i.e., accumulation of newly synthesized ureides and ureides not metabolized in shoots returning to nodules, which is consistent with the increases of ureides in leaves, petioles and nodules of plants exposed to drought. However, the increase of ureides in nodules was more evident, suggesting that most of the ureides accumulated in nodules had been recently synthesized.

Ladrera et al. (2007) found an early and more intense accumulation of ureides in 'Biloxi' nodules under drought, a drought-sensitive genotype, than in nodules from 'Jackson', an NFDT genotype. In the present study, the NFDT genotypes under drought showed higher concentrations of ureides in nodules than the susceptible genotypes. This suggests that the NFDT genotypes are intrinsically more effective in maintaining their capacity for $\mathrm{BNF}$, even with higher concentrations of ureides. As a result, shoot $\mathrm{N}$ accumulations were higher in NFDT genotypes, which were able to provide $\mathrm{N}$ for the formation of seeds (King and Purcell, 2006; King et al., 2014).
The increase of TSS in nodules under drought may result from a lower activity of SS, a key enzyme involved in the hydrolysis of sucrose in nodules. Lower activity may restrict the supply of energy involved in the reduction of $\mathrm{N}_{2}$. A decrease in SS activity in soybean nodules under drought first occurred in susceptible genotypes before occurring in the NFDT ones (Ladrera et al., 2007). Thus, decline in SS activity due to drought leads to accumulation of TSS in the nodules because of failure in the metabolism of $\mathrm{C}$. Consequently, a reduction in the supply of energy to the bacteroids impairs the BNF process.

Drought affected the metabolism of $\mathrm{C}$ more clearly in the susceptible genotypes. Despite the substantial accumulation of ureides in nodules of all genotypes, the NFDT genotypes showed better performance under drought. In particular, R01-581F had more stable physiological processes, more nutrient uptake, higher net photosynthetic rates, the highest chlorophyll concentration, and better N-metabolism, highlighting its NFDT trait. The genotypes R01-416F and R021325 also showed superior performance over the susceptible genotypes, but not as effectively as R01-581F.

Our results suggest that R01-581F has the potential to tolerate drought because of its ability to maintain physiological processes and BNF. This ability can be attributed to better osmotic regulation due to higher concentrations of $\mathrm{K}^{+}$, increase in root system, and better translocation/metabolization of ureides. These characteristics emphasize the potential of R01-581F for use in breeding programs aimed at increasing soybean drought-tolerance. Moreover, the analyses of ureides in petioles was a promising indicator for screening soybean genotypes with the NFDT phenotype.

\section{Acknowledgements}

The authors acknowledge Dr. Thomas R. Sinclair, Dra. Larissa A. C. Moraes and Dra. Glaciela Kaschuk for their critical review work on this manuscript. P. Cerezini acknowledges a M.Sc. fellowship from Coordination for the Improvement of Higher Level Personnel (CAPES). M.A. Nogueira and M. Hungria are Brazilian National Council for Scientific and Technological Development (CNPq) research fellows. This study was financed by the Brazilian Agricultural Research Corporation (Embrapa), project \#02.09.01.023.00.00, and by CNPq-Repensa, project \#562008/2010-1. This paper was approved for publication by the Editorial Board of Embrapa Soybean as manuscript number $26 / 2013$.

\section{References}

Arrese-Igor, C.; González, E.M.; Marino, D.; Ladrera, R.; Larrainzar, E.; Gil-Quintana, E. 2011. Physiological responses of legume nodules to drought. Plant Stress 5: 24-31.

Baker, N.R.; Rosenqvst, E. 2004. Applications of chlorophyll fluorescence can improve crop production strategies: an examination of future possibilities. Journal of Experimental Botany 55: 1607-1621. 
Bray, E.A. 1997. Plant responses to water deficit. Trends in Plant Science 2: 48-54.

Carvalho, M.A.M.; Pinto, M.M.; Figueiredo-Ribeiro, R.C.L. 1998. Inulin production by Vernonia herbacea as influenced by mineral fertilization and time of harvest. Brazilian Journal of Botany 21: 275-280.

Cerezini, P.; Pípolo, A.E.; Hungria, M.; Nogueira, M.A. 2014. Gas exchanges and biological nitrogen fixation in soybean under water restriction. American Journal of Plant Sciences 5: 40114017.

Chen, P.; Sneller, C.H.; Purcell, L.C.; Sinclair, T.R.; King, C.A.; Ishibashi, T. 2007. Registration of soybean germplasm lines R01-416F and R01-581F for improved yield and nitrogen fixation under drought stress. Journal of Plant Registrations 1 : 166-167.

Collier, R.; Tegeder, M. 2012. Soybean ureide transporters play a critical role in nodule development, function and nitrogen export. The Plant Journal 72: 355-367.

Fenta, B.A.; Driscoll, S.P.; Kunert, K.J.; Foyer, C.H. 2012. Characterization of drought-tolerance traits in nodulated soya beans: the importance of maintaining photosynthesis and shoot biomass under drought-induced limitations on nitrogen metabolism. Journal of Agronomy and Crop Science 198: 92103.

Guan, X.; Gu, S. 2009. Photorespiration and photoprotection of grapevine (Vitis vinifera L. cv. Cabernet Sauvignon) under water stress. Photosynthetica 47: 437-444.

Intergovernmental Panel on Climate Change [IPCC]. 2007. Climate change: the physical science basis. Contribution of Working Group I to the Fourth Assessment Report of the Intergovernmental Panel on Climate Change. Available at: http://www.ipcc.ch [Accessed Nov 19, 2011]

James, A.T.; Lawn, R.J.; Cooper, M. 2008. Genotypic variation for drought stress response traits in soybean. II. Inter-relations between epidermal conductance, osmotic potential, relative water content, and plant survival. Australian Journal of Agricultural Research 59: 670-678.

Kaschuk, G.; Hungria, M.; Leffelaar, P.A.; Giller, K.E.; Kuyper, T.W. 2010. Differences in photosynthetic behaviour and leaf senescence of soybean [Glycine $\max$ (L.) Merrill] dependent on $\mathrm{N}_{2}$ fixation or nitrate supply. Plant Biology 12: 60-69.

King, C.A.; Purcell, L.C. 2001. Soybean nodule size and relationship to nitrogen fixation response to water deficit. Crop Science 41: 1099-1107.

King, C.A.; Purcell, L.C. 2006. Genotypic variation for shoot N concentration and response to water deficits in soybean. Crop Science 46: 2396-2402.

King, C.A.; Purcell, L.C.; Bolton, A.; Specht, J.E. 2014. A possible relationship between shoot $\mathrm{N}$ concentration and the sensitivity of $\mathrm{N}_{2}$ fixation to drought in soybean. Crop Science 54: 746-756.
Ladrera, R.; Marino, D.; Larrainzar, E.; González, E.M.; ArreseIgor, C. 2007. Reduced carbon availability to bacteroids and elevated ureides in nodules, but not in shoots, are involved in the nitrogen fixation response to early drought in soybean. Plant Physiology 145: 539-546.

Lopes, M.S.; Araus, J.L.; Van-Heerden, P.D.R.; Foyer, C.H. 2011. Enhancing drought tolerance in $\mathrm{C}_{4}$ crops. Journal of Experimental Botany 62: 3135-3153.

McCormick, A.J.; Cramer, M.D.; Watt, D.A. 2008. Changes in photosynthesis rates and gene expression of leaves during a source-sink perturbation in sugarcane. Annals of Botany 101: 89-102.

Ohashi, Y.; Nakayama, N.; Saneoka, H.; Fujita, K. 2006. Effects of drought stress on photosynthetic gas exchange, chlorophyll fluorescence and stem diameter of soybean plants. Biologia Plantarum 50: 138-141.

Purcell, L.C.; King, C.A.; Ball, R.A. 2000. Soybean cultivar differences in ureides and the relationship to drought tolerant nitrogen fixation and manganese nutrition. Crop Science 40: 1062-1070.

Richards, L.A.; Fireman, M. 1943. Pressure plate apparatus for measuring water sorption and transmission by soils. Soil Science 56: 395-400.

Searle, P.L. 1984. The Berthelot or indophenol reaction and its use in the analytical chemistry of nitrogen. Analyst 109: 549-568.

Sinclair, T.R.; Purcell, L.C.; King, A.; Sneller, C.H.; Chen, P.; Vadez, V. 2007. Drought tolerance and yield increase of soybean resulting from improved symbiotic $\mathrm{N}_{2}$ fixation. Field Crops Research 101: 68-71.

Sinclair, T.R.; Vadez, V. 2012. The future of grain legumes in cropping systems. Crop and Pasture Science 63: 501-512.

Streeter, J.G. 2003. Effects of drought on nitrogen fixation in soybean root nodules. Plant, Cell and Environment 26: 11991204.

Thu, N.B.A.; Nguyen, Q.T.; Hoang, X.L.T.; Thao, N.P.; Tran, L.S.P. 2014. Evaluation of drought tolerance of the Vietnamese soybean cultivars provides potential resources for soybean production and genetic engineering. BioMed Research International 2014: 1-9.

Vadez, V.; Sinclair, T.S.; Serraj, R. 2000. Asparagine and ureide accumulation in nodules and shoots as feedback inhibitors of $\mathrm{N}_{2}$ fixation in soybean. Physiologia Plantarum 110: 215-223.

Vadez, V.; Sinclair, T.R. 2002. Sensitivity of $\mathrm{N}_{2}$ fixation traits in soybean cultivar Jackson to manganese. Crop Science 42: 791796.

Vogels, G.D.; van der Drift, C. 1970. Differential analysis of glyoxylate derivatives. Analytical Biochemistry 33: 143-157.

Yemm, E.W.; Willis, A.J. 1954. The estimation of carbohydrates in plant extracts by anthrone. Biochemical Journal 57: 508-514. 